\title{
Coulisses
}

Revue de théâtre

\section{Les Premières Rencontres internationales Théâtre et Université de Franche-Comté}

Rédaction

\section{(2) OpenEdition}

1 Journals

Édition électronique

URL : http://journals.openedition.org/coulisses/1621

DOI : $10.4000 /$ coulisses. 1621

ISSN : 2546-9460

Éditeur

Presses universitaires de Franche-Comté

\section{Édition imprimée}

Date de publication : 1 février 1991

Pagination : 4-8

ISSN : 1150-594X

\section{Référence électronique}

Rédaction, « Les Premières Rencontres internationales Théâtre et Université de Franche-Comté »,

Coulisses [En ligne], 3 | Hiver 1991, mis en ligne le 04 juillet 2017, consulté le 22 octobre 2019. URL:

http://journals.openedition.org/coulisses/1621 ; DOI : 10.4000/coulisses.1621

Ce document a été généré automatiquement le 22 octobre 2019.

Coulisses 


\title{
Les Premières Rencontres internationales Théâtre et Université de Franche-Comté
}

\author{
Rédaction
}

\section{Bilan et perspectives}

1 Organisées du 17 au 21 Avril 1990, les Premières Rencontres internationales « Théâtre et Université » ont présenté à Besançon les spectacles de onze théâtres universitaires et de trois troupes professionnelles et proposé huit ateliers à tendance théorique, c'est-àdire orientés vers la recherche, ou pratique (comptes rendus d'expériences) animés par universitaires, professionnels ou metteurs en scène.

2 Les quelques mille trois cents spectateurs, de même que les sept observateurs Bulgares, Tchèques et Lituaniens, ainsi que les trois de l'Université de Nancy et les cinq de l'INSA de Rouen, ont ainsi pu assister aux représentations des troupes des universités de Nice, Aix en Provence, Grenoble, Dijon, Paris III, Paris X-Nanterre, Paris VIII-Saint Denis et Besançon (pour ce qui est de la France) de Liège, Bruxelles, Murcie, Cologne et Neuchâtel, et des compagnies professionnelles de la Boutique des Contes, du Théâtre populaire jurassien et du Théâtre du funambule de Hull (Québec). 


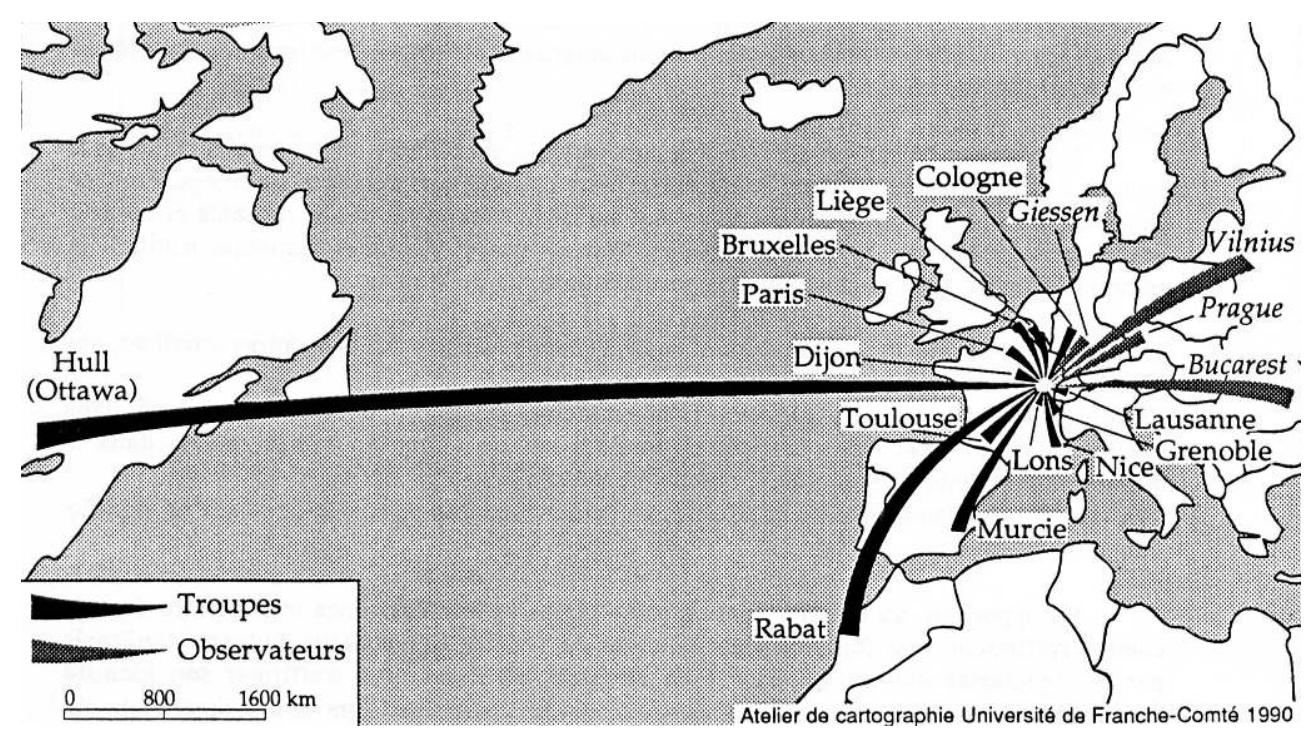

(C) Atelier de cartographie université de Franche-Comté, 1990.

\section{L'université : un lieu d'échange et de confrontation de la pratique et de la réflexion sur le théâtre}

Organisées à titre bénévole par amateurs, enseignants et étudiants en stage, les rencontres ont prouvé qu'il y avait une place pour un lieu d'échange et de confrontation de la pratique et de la réflexion sur le théâtre à l'université, qu'il convient de créer d'une part, et de faire durer d'autre part, par une politique de formation et d'échanges culturels entre professionnels, universitaires et étudiants, d'origine sociale, de nationalité, de formation et d'horizons variés Ce Théâtre universitaire de Franche-Comté a ainsi été invité en retour aux festivals de Rokiskis (Lituanie) de Cologne et de Bulgarie, et conclu une politique d'échanges avec Hull et l'Europe de l'Est).

\section{Un panorama de l'activité théâtrale a l'université...}

4 Puisqu'aucune sélection des spectacles n'a été opérée, la programmation très variée, a offert un tableau représentatif de ce qui se fait actuellement, qu'il s'agisse des thèmes les plus prisés, des différentes façons de les exprimer ou des diversités de fonctionnement. Elles ont de surcroît été l'occasion d'un dialogue Est-Ouest et NordSud abolissant toutes les frontières avec pour unique objectif, la célébration d'une passion commune : le théâtre.

\section{... révélant un faible engagement... et la redondance de certains thèmes}

Il s'avère dès lors possible de dresser un panorama de l'idéologie à l'université lourde institution, fermée sur elle-même mais qui peut devenir un espace de liberté, au sein duquel de nombreuses réalisations peuvent être entreprises, à condition toutefois de le vouloir. Cependant, si les étudiants semblent souvent pleins de volonté et 
d'enthousiasme, il n'osent pas toujours exprimer leurs aspirations: problèmes d'exclusion et notion d'engagement, l'Université demeure le reflet du monde dans lequel nous vivons. On a ainsi pu observer une certaine distance vis à vis des problèmes d'aujourd'hui, tendance que l'on retrouve dans le phénomène associatif; aux associations à vocation essentiellement militantiste ont succédé des associations de distraction... Mai 68 semble bel et bien enterré et grandes causes, questions morales ou autres problèmes de société ne trouvent guère leur place face à une certaine redondance des thèmes : on prône alors métaphysique, sexualité et religion.

\section{Des modes d'expression variés...}

On note cependant de grandes différences quant à la manière de les exprimer : alors que certains privilégient texte, mots, jeu et technique du comédien, d'autres préfèrent le langage du corps pour transmettre l'émotion, à l'image des Européens de l'Est. L'effort d'imagination se situe donc davantage dans la façon de dire les choses, et l'on assiste à la naissance d'un langage. résidant dans l'importance du rapport au public, de l'expression de "paroles vraies », car issues d'amateurs.

\section{Mais une certaine timidité quant à l'innovation}

7 Le théâtre français semble cependant figé et les étrangers d'avantage ouverts à une nouvelle esthétique : bien que jeunes, les étudiants innovent peu et l'on retient parfois une impression de « déjà vu » (surréalistes, années soixante dix). Certes l'on demeure tributaire d'une lourde tradition théâtrale mais celle-ci justifie-t-elle le vide ressenti en ce qui concerne la création ou l'interprétation de jeunes auteurs?

8 Notons au préalable que ces derniers se gardent bien, en général, de solliciter les amateurs, préférant trouver reconnaissance et légitimation de leur oeuvre auprès des professionnels. D'autre part, n'est-il pas aussi risqué - et innovant - de reprendre une pièce traditionnelle du répertoire - Sophocle par exemple - en y jetant un regard nouveau, et en s'exposant à une critique d'autant plus exigeante qu'elle dispose d'éléments de comparaison?

\section{Le travail collectif : un enrichissement par la pratique}

Même si l'on peut parfois reprocher à certaines interprétations de trop «coller au texte » et déplorer l'absence de recul à son égard, le travail collectif avec les acteurs permet un enrichissement par la pratique, bien qu'il demeure impossible, en raison de leur nombre et du temps disponible, d'explorer les possibilités de chaque comédien individuellement. Enthousiasme et tempérament des acteurs se trouvent canalisés dans la mise en scène, qui utilise leurs compétences et leurs maladresses pour porter sur scène et communiquer un texte.

\section{Des approches du théâtre différentes}

10 Cependant, si le fond est identique (volonté de dire les choses, travail collectif, épanouissement et enrichissement personnel) les modes de fonctionnement et les 
approches de théâtre diffèrent. Si pour certains, chacun doit avoir sa partition dans un système à peu près équivalent, d'autres troupes fonctionnent avec des textes, privilégiant quelques rôles clefs, entourés de figurants.

\section{Une manifestation appréciée...}

11 En conclusion, malgré quelques problèmes techniques (on observe en général un certain manque de compétence en régie dans la plupart des théâtres universitaires ainsi qu'une carence en matériel...), l'organisation, qu'il s'agisse de l'accueil réservé aux participants ou des animations (spectacles et ateliers), a été fort appréciée.

Très prometteuses, ces rencontres inaugurales ont permis de dresser un état des lieux de l'activité théâtrale à l'Université et ont été l'occasion d'un échange interculturel.

\section{... à l'avenir prometteur}

Révélatrices de la vitalité et de la qualité de la création théâtrale à l'Université, elles devraient rendre possible l'élaboration de liens - d'autant plus fructueux, que les acteurs y trouvent l'occasion de se constituer en spectateurs - entre réflexion Universitaire et pratique théâtrale et la naissance et l'entretien d'un dialogue entre recherche théorique et pratique théâtrale.

Les perspectives sont ainsi fort encourageantes, notamment dans le cadre des relations internationales et de la recherche (échanges avec le séminaire d'études théâtrales de Neuchâtel, organisation d'un week-end de travail sur le thème "Théâtre et Poésie » à Besançon avec Paris VIII).

\section{... et la suite ?}

Puisqu'elles correspondent à une attente, les rencontres se doivent d'être renouvelées, et l'expérience de cette première permettra d'en améliorer l'organisation. La présence de professionnels s'avère ainsi nécessaire (formations, comparaison) de même que celle d'auteurs ; la nécessité d'un retour critique sur les spectacles a, en outre, été mise en lumière.

Il a paru intéressant d'alterner « rencontres générales » et « rencontres spécialisées ».

Le thème proposé pour 1991 serait «Théâtre et Poésie » et chaque spectacle présenté serait ensuite « mis en pièces " par des critiques.

C'était une belle fête des Théâtres, une vraie joie pour chaque amateur du Théâtre de n'importe quelle nationalité.

Jonas (observateur lituanien). 